\title{
Patient discharge from intensive care: an updated scoping review to identify tools and practices to inform high-quality care
}

Kara M. Plotnikoff ${ }^{1}$, Karla D. Krewulak', Laura Hernández ${ }^{1}$, Krista Spence ${ }^{1}$, Nadine Foster $^{1}$, Shelly Longmore ${ }^{1}$, Sharon E. Straus ${ }^{2,3}$, Daniel J. Niven ${ }^{1,4}$, Jeanna Parsons Leigh ${ }^{1,5}$, Henry T. Stelfox ${ }^{1,4}$ and Kirsten M. Fiest ${ }^{1,4,6,7^{*}}$ (D)

\begin{abstract}
Background: Critically ill patients require complex care and experience unique needs during and after their stay in the intensive care unit (ICU). Discharging or transferring a patient from the ICU to a hospital ward or back to community care (under the care of a general practitioner) includes several elements that may shape patient outcomes and overall experiences. The aim of this study was to answer the question: what elements facilitate a successful, highquality discharge from the ICU?
\end{abstract}

Methods: This scoping review is an update to a review published in 2015. We searched MEDLINE, EMBASE, CINAHL, and Cochrane databases from 2013-December 3, 2020 including adult, pediatric, and neonatal populations without language restrictions. Data were abstracted using different phases of care framework models, themes, facilitators, and barriers to the ICU discharge process.

Results: We included 314 articles from 11,461 unique citations. Two-hundred and fifty-eight (82.2\%) articles were primary research articles, mostly cohort $(118 / 314,37.6 \%)$ or qualitative $(51 / 314,16.2 \%)$ studies. Common discharge themes across all articles included adverse events, readmission, and mortality after discharge (116/314, 36.9\%) and patient and family needs and experiences during discharge (112/314, 35.7\%). Common discharge facilitators were discharge education for patients and families (82, 26.1\%), successful provider-provider communication (77/314, 24.5\%), and organizational tools to facilitate discharge $(50 / 314,15.9 \%)$. Barriers to a successful discharge included patient demographic and clinical characteristics (89/314, 22.3\%), healthcare provider workload (21/314,6.7\%), and the impact of current discharge practices on flow and performance (49/314, 15.6\%). We identified 47 discharge tools that could be used or adapted to facilitate an ICU discharge.

Conclusions: Several factors contribute to a successful ICU discharge, with facilitators and barriers present at the patient and family, health care provider, and organizational level. Successful provider-patient and provider-provider communication, and educating and engaging patients and families about the discharge process were important factors in a successful ICU discharge.

Keywords: Critical care, Intensive care, Transitions in care, Quality of care, Patient discharge

\footnotetext{
*Correspondence: kmfiest@ucalgary.ca

${ }^{1}$ Department of Critical Care Medicine, Cumming School of Medicine,

University of Calgary and Alberta Health Services, 3134 Hospital Drive NW, Calgary, AB T2N 4Z6, Canada
}

Full list of author information is available at the end of the article

\section{Background}

Transitions in care occur when a patient is being moved between healthcare settings (e.g., intensive care unit [ICU] to hospital ward) or providers (e.g., changes in nursing shift) [1]. Transitions in care are complex, original author(s) and the source, provide a link to the Creative Commons licence, and indicate if changes were made. The images or other third party material in this article are included in the article's Creative Commons licence, unless indicated otherwise in a credit line to the material. If material is not included in the article's Creative Commons licence and your intended use is not permitted by statutory regulation or exceeds the permitted use, you will need to obtain permission directly from the copyright holder. To view a copy of this licence, visit http://creativecommons.org/licenses/by/4.0/. The Creative Commons Public Domain Dedication waiver (http://creativeco mmons.org/publicdomain/zero/1.0/) applies to the data made available in this article, unless otherwise stated in a credit line to the data. 
requiring communication and coordination of care between multiple healthcare providers [1]. Incomplete or inaccurate transfer of information between healthcare providers during transitions in care may result in unnecessary healthcare utilization (e.g., unnecessary medications[2] or low-value care[3]), adverse events[4, $5]$, medical errors [2, 4] and poor patient and family satisfaction of care [6-10].

Transitions in care of critically ill patients from the ICU are even more complex because they include a change of care setting and often include a change in health status[11] characterized by severe illness [12], exacerbation of chronic medical problems [13], and newly acquired physical[12] (e.g., weakness) and psychiatric[12] (e.g., delirium) injuries. While some institutions have ICU discharge guidelines, their consistent application in practice varies [14-17]. Differences between ICU and ward care may also make transitions in care challenging; this includes patients transitioning from a unit with specialized technology and monitoring and lower nurse to patient ratios (ICU) to a less acute environment with higher nurse to patient ratios (ward) [18-20].

Admission to an ICU and subsequent transitions in care impact many patients and caregivers each year [2124]. By improving transitions in care, patients and families may feel more satisfied with care [25], and may have fewer adverse outcomes including re-hospitalizations [4, 5]. The quality of transitions in care is one metric used by the World Health Organization (WHO) and Joint Commission International (JCI) to evaluate hospital performance [26]. As such, the transitions in care literature has rapidly evolved over the past five years. A scoping review from our team published in 2015 reviewed the transitions in care literature and identified 224 articles that described discharge themes and patient, provider, and institutional factors that act as facilitators and/or barriers to patient care during transitions in care [27]. A recent scoping review of 37 articles described the transitions of adult ICU populations to inpatient wards [18]. The authors reported practices that had positive (e.g., adequate communication between ICU and ward staff) and negative (e.g., afterhours or weekend discharges) impacts on the transition in care from the ICU to a hospital ward [18]. Our review includes these elements, and adds to the literature by summarizing current evidence and practices around transitions in care of critically ill neonatal, pediatric, and adult populations. Our review also includes transitions in care from the ICU to a hospital ward, and transitions in care directly back to the community, a practice becoming increasingly common at some institutions [28-30]. We also provide an overview of tools used in these settings to facilitate successful transitions in care.

\section{Methods}

We followed scoping review frameworks by Arksey and O'Malley[31] and Levac and colleagues[32] to update the previous scoping review by Stelfox and colleagues in 2015 [27]. We followed the Preferred Reporting Items for Systematic reviews and Meta-Analyses extension for Scoping Reviews (PRISMA-ScR; see Additional File 1) [33].

\section{Search strategy}

We searched MEDLINE, EMBASE, CINAHL, and Cochrane Reviews Databases on December 3, 2020, basing our search strategy on the 2015 scoping review [27]. The search was restricted from 2013-present with no language restrictions. The MEDLINE search strategy is available in Additional file 2. Results were downloaded and imported into reference management software EndNote Version X9 (Clarivate Analytics, Philadelphia, PA, USA, 2013) and were managed using Microsoft Excel (Microsoft Corporation, 2016).

\section{Article selection}

Articles were included if they were peer-reviewed, described adult, pediatric, or neonatal populations, and primarily focused on the structure, process, or outcome of discharge (e.g., the decision to discharge a patient on home mechanical ventilation or not, the use of a guideline or checklist during discharge, or evaluating patient outcomes based on differences in the time of day discharge occurred, respectively) as defined by the Donabedian model for evaluating quality of healthcare [34, $35]$. Articles were excluded if they were included in the 2015 scoping review [27].

Populations in included studies could be patients, family members or other caregivers of patients, or healthcare providers (e.g., physicians, nurses, allied healthcare providers). We included both primary (e.g., cohort, qualitative, and cross-sectional studies) and secondary research articles (e.g., reviews, editorials, and consensus methodologies). Articles were excluded if they described transfers between ICUs, transfers to ICUs (e.g., transfers from a coronary care unit, intermediate unit, or step-down unit), did not primarily discuss the structure, process, or outcome of an ICU discharge, or if we were unable to find the full-text article. Two research assistants piloted the inclusion and exclusion criteria with 100 titles and abstracts to ensure the criteria were applied consistently. Six research assistants reviewed each title and abstract independently and in duplicate. If either reviewer indicated that the reference should move on to full-text review, it was included.

After piloting inclusion and exclusion criteria on $10 \%$ of full-text articles to ensure consistency across research assistants, all full-text articles were reviewed 
independently and in duplicate. If consensus could not be reached between the two research assistants, a third was consulted. If articles were not available in English, they were translated using Google Translate, [36] which has been shown to be a reliable tool for translating documents for systematic reviews [37].

\section{Data abstraction and analysis}

After piloting a standardized form in Excel, research assistants abstracted data from each article, which included study information (e.g., location, study dates, study design) and ICU characteristics (e.g., population, speciality). Articles were classified as primary research (e.g., cohort, qualitative, cross-sectional, randomized controlled trials $[\mathrm{RCT}]$, other non-RCT interventional studies, case study or series, scoping or systematic reviews including meta-analyses) or secondary and descriptive research (e.g., narrative or literature reviews, consensus methodologies using existing literature, opinion pieces). Each article was classified according to the phase of care examined, Donabedian framework stage (process, structure, or outcome of discharge) [34, 35], and the Institute of Medicine (IoM) Health Care Quality Framework (safe, effective, efficient, timely, patientcentered, equitable) [38]. Articles were assessed based on ICU discharge themes including adverse events, readmission, and mortality following discharge, patient and family needs and experiences during discharge, amongst others. Discharge facilitators and barriers were assessed at a patient and family level, a provider level, and at an organizational level. For themes, facilitators, and barriers, reviewers categorized each article from a pre-established framework, and could indicate if additional elements were present in the article. Figure 1 and Table 1 provide a summary and example for each framework and theme. Each article was screened for tools that could facilitate a successful ICU discharge. Tools could be guidelines or checklists, transfer tools, educational tools, discharge assessments, discharge letters, transfer brochures, prediction tools, triage models, or peer support programs. Descriptions of each type of tool is available in Additional File 3.

Abstracted data was verified by another research assistant. Discrepancies between reviewers were discussed, and a third reviewer was consulted if needed. Data analyses were completed using STATA version 14.2 for Windows (StataCorp LP, College Station, Texas, USA, 2015). Aligning with scoping review methodology [31, 32], articles were not assessed for quality or risk of bias.

\section{Results}

The search identified 11,461 unique articles (Fig. 2). Of these, we reviewed 2,024 full-text articles; 314 articles were included in the review. The most common reason articles were excluded was because they did not focus primarily on the structure, process, or outcome of ICU discharge $(n=1,338,78.2 \%)$ or we could not retrieve the full-text, English version of the article (includes one article that could not be translated from Persian to English[39], and 16 protocol registrations of which a subsequent full-text publication could not be found. The remaining were 184 citations where only conference abstracts were available, and 13 articles we were unable to obtain from foreign journals; $\mathrm{n}=214,12.5 \%$; Fig. 2).

\section{Description of the articles}

There were $269(85.7 \%)$ primary research articles and 45 (14.3\%) secondary or descriptive articles (Table 2). Most primary research articles were retrospective or prospective cohort studies $(118 / 269,43.9 \%)$ or qualitative studies (51/269, 19.0\%). Most secondary research articles were literature or narrative reviews (35/45, 77.8\%). Articles were mainly from North American and European countries $(135 / 314,43.0 \%$ and $80 / 314,25.5 \%$, respectively), and published in English (304/314, 96.8\%). Articles focused on adult ICU $(162 / 314,51.6 \%)$, neonatal (97/314, $30.9 \%)$, or pediatric patients $(34 / 314,10.8 \%)$, with some studies including more than one population. Thirty-one studies (9.9\%) did not state a specific age for the included population, nor could this be inferred from the included patient demographic information. Most adult ICUs were medical $(79 / 314,25.2 \%)$ or surgical $(73 / 162,23.3 \%)$. Article characteristics are described in Table 2.

\section{Patient care frameworks}

Phases of care examined, Donabedian framework elements, and IoM framework elements for each article are summarized in Table 3. Phases of care include execution of discharge (185/314, 58.9\%), post-discharge followup (159/314, 50.6\%), planning for discharge (93/314, 29.6\%), and evaluation for discharge (i.e., patient readiness; 42/314, 13.4\%). Most articles reported on the Donabedian framework element of process of discharge $(199 / 314,63.4 \%)$ followed by the outcome (159/314, $50.6 \%)$, and structure of discharge $(94 / 314,29.9 \%)$.The most common IoM framework element in included articles was safety $(161 / 314,51.3 \%)$, followed by patientcenteredness (153/314, 48.7\%). Additional dimensions were effective $(112 / 314,35.7 \%)$, efficient $(85 / 314,27.1 \%)$ timely $(54 / 314,17.2 \%)$, or equitable $(5 / 314,1.6 \%)$ elements of care.

There were differences in each of the frameworks' elements when comparing adult, pediatric, and neonatal 

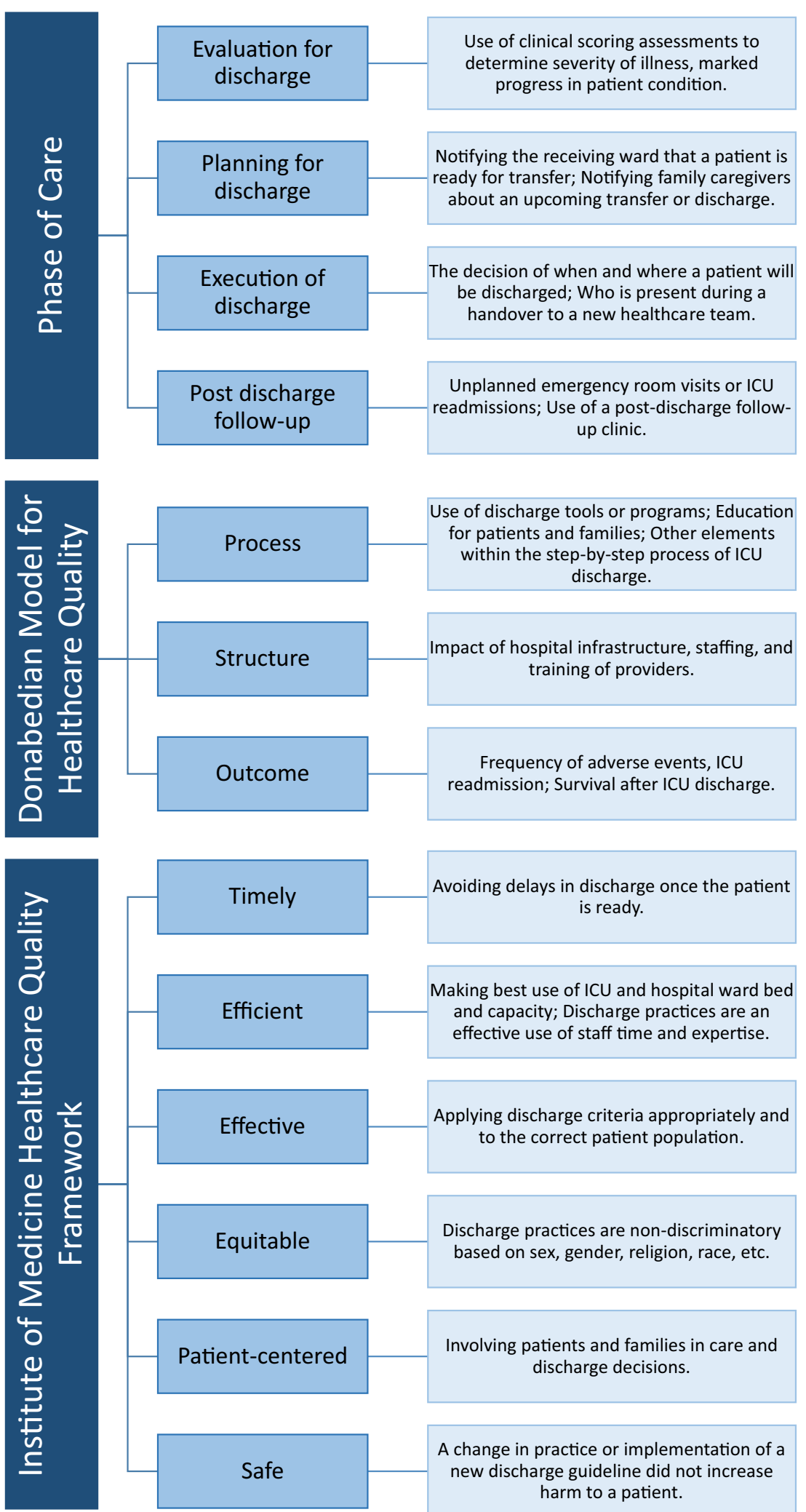

Avoiding delays in discharge once the patient is ready.

Making best use of ICU and hospital ward bed and capacity; Discharge practices are an effective use of staff time and expertise.

Applying discharge criteria appropriately and to the correct patient population.

Discharge practices are non-discriminatory based on sex, gender, religion, race, etc.

Involving patients and families in care and discharge decisions.

A change in practice or implementation of a new discharge guideline did not increase harm to a patient.

Fig. 1 Framework elements and examples used for article classification 
Table 1 Summary of data abstraction for themes, and facilitators and barriers to a successful transition in care

Theme Example

ICU Discharge Themes

Adverse events, readmission, and mortality following discharge

Patient and family needs and experiences during discharge

ICU or emergency department readmission rates; Mortality following ICU discharge in a given time frame (e.g., one year after discharge)

Planning for discharge

Patients or families desire for more information about the next steps in care; Appreciation for the attentiveness of nursing staff in ICU

Continuity of patient care

Notifying subsequent care providers about the patient's condition; Aligns with planning for discharge in the phase of care model

Continuity of patient care

Discharge education for patients and families

Standardizing the discharge process

Availability of complete and accurate discharge information

Evaluating patient readiness for discharge

Anxiety associated with discharge

Timeliness of discharge

Resource use during discharge

Critical care transition program

Medication reconciliation

Autonomy

Discharge education for providers

Facilitators for a successful ICU discharge

Patients and family

Use of a transition program or follow-up clinics - patients understand where to seek care after ICU discharge

Programs that provide information on what is to be expected after discharge and when to seek medical help

Use of guidelines or protocols to ensure the discharge process is the same for all patients

Use of medical records, checklists, or summaries to provide appropriate information to either healthcare providers, family members, or patients

Use of clinical scoring assessments to determine severity of illness, marked progress in patient condition; Aligns with phase of care examined

Patient or family feelings of anxiousness about transitioning to a different level of care or worrying about leaving the ICU

Time of day discharge occurs (daytime versus nighttime), and if there is a delay in discharge (patient has been ready for discharge for several days but has not been transitioned out of ICU)

Use of supplies, infrastructure, or staff time to facilitate the discharge

Presence of a dedicated team that works with ICU and the receiving care providers to improve the transition. May include a nurse liaison or outreach team

Verifying that medications started in the ICU should be continued after discharge

Patients feeling like they have a say in their discharge and/or subsequent care

Programs that teach ward staff what to expect from an ICU patient; Education for ICU providers about facilitating a successful ICU discharge

Discharge education for patients and families; Family engagement/support system; Provider-patient communication; Patient demographic and clinical characteristics; Written communication for patients and families; Expectations of patients/family; Patient/family are treated as members of the healthcare team; Patient/family feelings of self-efficacy; Use of coping mechanisms; Excited, joyous to be leaving the ICU

Healthcare providers Provider-provider communication; Critical care transition programs (e.g., outreach, liaison nurse); Collaboration between ICU and ward; Written documentation for providers; Knowledge/experience of provider; Clinical judgment or decision-making; Clear roles/responsibility for providers; Multidisciplinary team; Provider leadership; Provider empathy to patient and family

Organization

Tools to facilitate discharge; Impact of current discharge practices on flow and performance; Guidelines or policies; Use of best practices; Discharge location from ICU; Education/training of providers; Time of discharge (day of week or time of day); Availability of follow-up clinics or home support programs; Admission location before ICU; Hospital characteristics (e.g., trauma level);

Barriers to a successful ICU discharge Patients and family

Patient demographic and clinical characteristics; Feelings of patient and family anxiety, embarrassment; Expectations of patients/family; Physical and psychological effects of illness (e.g., pain, nightmares; Lack of provider-patient communication; ICU and hospital length of stay; Financial obstacles (lack of insurance, cost of care); Socioeconomic factors of patient/ family; Logistical barriers to providing support (e.g., family lives far from hospital); Lack of familial support; Feelings of lack of control

Healthcare providers 
Table 1 (continued)

\begin{tabular}{|c|c|}
\hline Theme & Example \\
\hline Organization & $\begin{array}{l}\text { Impact of current discharge practices on flow and performance; Delay in discharge; } \\
\text { Time of discharge (day of week or time of day); Limited ICU and ward resources; Costs } \\
\text { of healthcare provided; Hospital characteristics (e.g., trauma level); Hospital or ICU } \\
\text { capacity; Admission location before ICU; Physical and technological infrastructure } \\
\text { (small patient rooms, no electronic health records; Lack of education/training of pro- } \\
\text { viders; Reduction in the levels of technology and monitoring when transition from ICU } \\
\text { to ward; Restricted visitation policies }\end{array}$ \\
\hline
\end{tabular}

\section{PRISMA PRISMA 2009 Flow Diagram}
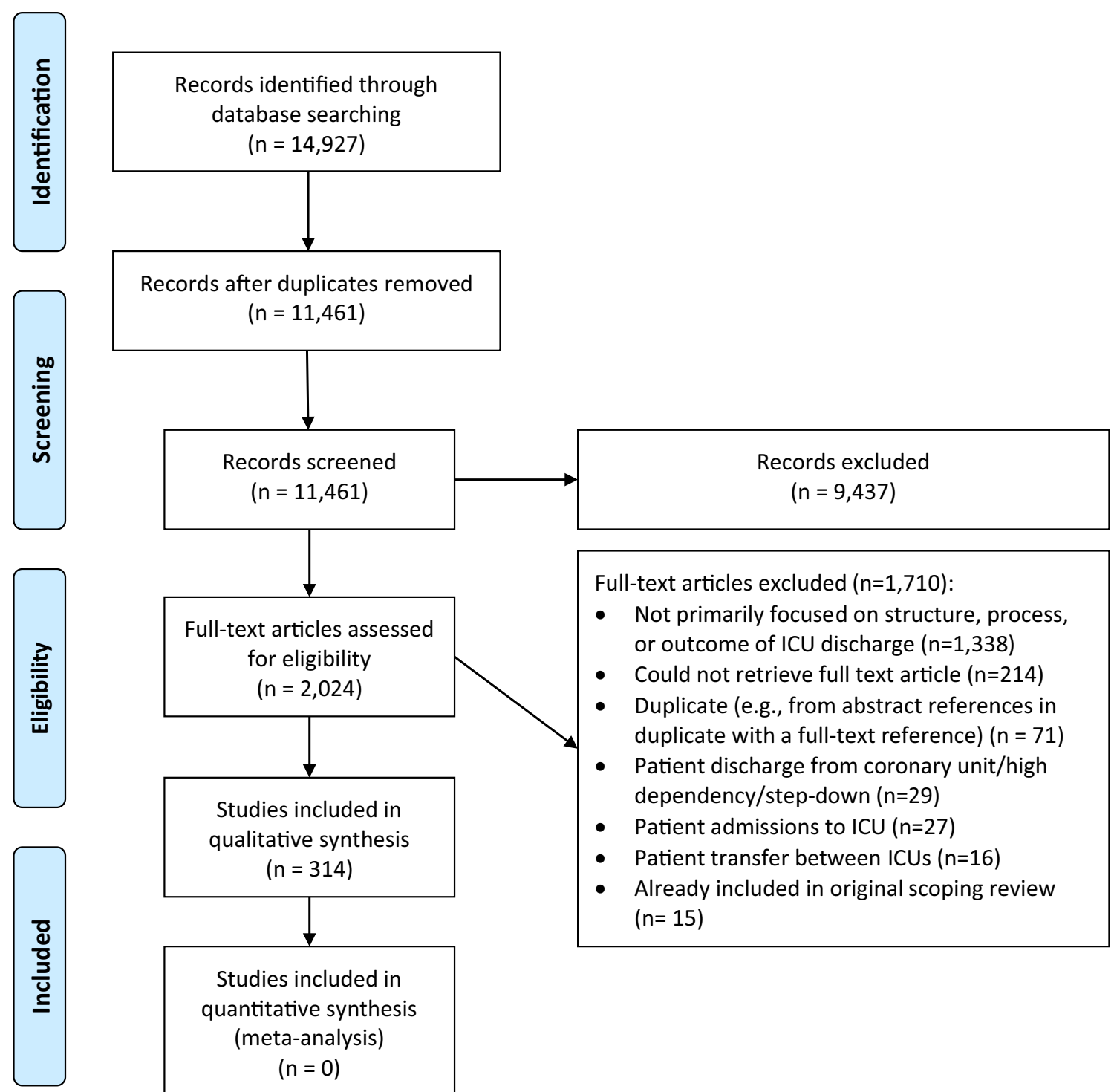

Full-text articles excluded $(n=1,710)$ :

- Not primarily focused on structure, process, or outcome of ICU discharge $(n=1,338)$

Full-text articles assessed for eligibility

( $n=2,024)$

- Could not retrieve full text article $(n=214)$

- Duplicate (e.g., from abstract references in duplicate with a full-text reference) $(n=71)$

- Patient discharge from coronary unit/high

Studies included in qualitative synthesis

$$
(n=314)
$$

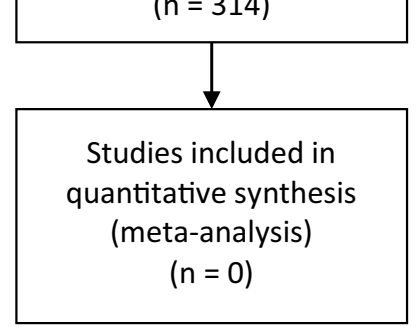
dependency/step-down ( $\mathrm{n}=29)$

- Patient admissions to ICU $(n=27)$

- Patient transfer between ICUs ( $n=16)$

- Already included in original scoping review $(n=15)$

Fig. 2 PRISMA flow diagram 
Table 2 Characteristics of included articles

\begin{tabular}{|c|c|}
\hline Characteristic & $\begin{array}{l}\text { All studies, } n \\
(\%)(N=314)\end{array}$ \\
\hline \multicolumn{2}{|l|}{ Type of study } \\
\hline \multicolumn{2}{|l|}{ Primary research } \\
\hline Cohort studies & $118(37.6)$ \\
\hline Qualitative study & $51(16.2)$ \\
\hline Interventional (non-RCT) & $39(12.4)$ \\
\hline Cross-sectional & $28(8.9)$ \\
\hline Systematic and scoping reviews ${ }^{\mathrm{a}}$ & $11(3.5)$ \\
\hline Randomized controlled trial & $8(2.6)$ \\
\hline Mixed methods & $8(2.6)$ \\
\hline Case study or series & $6(1.9)$ \\
\hline \multicolumn{2}{|l|}{ Secondary research } \\
\hline Literature and narrative reviews & $23(7.3)$ \\
\hline Descriptive studies & $7(2.2)$ \\
\hline Guidelines & $6(1.9)$ \\
\hline Delphi methodology and consensus statements & $5(1.6)$ \\
\hline Opinion & $4(1.3)$ \\
\hline \multicolumn{2}{|l|}{ Continent of Origin } \\
\hline North America & $135(43.0)$ \\
\hline Europe & $80(25.5)$ \\
\hline Asia & $35(11.2)$ \\
\hline Oceania & $23(7.3)$ \\
\hline Various (multiple) continents & $16(5.1)$ \\
\hline South America & $10(3.2)$ \\
\hline Africa & $1(0.3)$ \\
\hline Not reported & $14(4.5)$ \\
\hline \multicolumn{2}{|l|}{ Language } \\
\hline Published in English & $304(96.8)$ \\
\hline Non-English language publication & $10(3.2)$ \\
\hline \multicolumn{2}{|l|}{ Year of publication } \\
\hline $2012-2015^{b}$ & $98(31.2)$ \\
\hline 2016-2018 & $110(35.0)$ \\
\hline 2019-2021 & $106(33.8)$ \\
\hline \multicolumn{2}{|l|}{ Study population ${ }^{c}$} \\
\hline Adult & $162(51.6)$ \\
\hline Pediatric & $34(10.8)$ \\
\hline Neonatal & $97(30.9)$ \\
\hline Not reported & $31(9.9)$ \\
\hline \multicolumn{2}{|l|}{ Type of ICUa } \\
\hline Medical & $79(25.2)$ \\
\hline Surgical & $73(23.3)$ \\
\hline General system & $30(9.6)$ \\
\hline Cardiac & $23(7.3)$ \\
\hline Neurological & $21(6.7)$ \\
\hline Trauma & $19(6.1)$ \\
\hline Oncologic & $8(2.6)$ \\
\hline Burn & $4(1.3)$ \\
\hline Mixed (with sub-types not specified) & $2(0.6)$ \\
\hline Not reported & 80 (25.5) \\
\hline
\end{tabular}

Table 2 (continued)

\author{
ICU intensive care unit, $R C T$ randomized controlled trial \\ ${ }^{a}$ Includes integrative reviews \\ ${ }^{\text {b }}$ While the search was restricted to 2013 , late indexing brought forward articles \\ with an official publishing date of 2013 \\ ${ }^{\mathrm{c}}$ Reponses are not mutually exclusive and add up to more than $100 \%$
}

populations. For example, studies in adult populations more frequently reported on the outcome of discharge $(105 / 162,64.8 \%)$, when compared to pediatric (11/34, $32.4 \%$ ) and neonatal populations (36/97, 37.1\%). Neonatal populations reported on the execution of, and planning for, discharge (50/97, 51.5\% for both), whereas only $17.3 \%$ of adult populations were classified as planning for discharge (28/162). The least commonly reported IoM Framework element across all groups was equity (adult: $1 / 162$, $0.6 \%$; pediatric: $0 / 34,0 \%$; neonatal: $3 / 97,3.1 \%$ ) (Table 3). A complete overview of phase of care and framework elements is available in Additional File 4.

\section{ICU discharge themes}

The most common ICU discharge theme was adverse events $(116 / 314,36.9 \%)$, and patient and family needs and experiences during discharge $(112 / 314,35.7 \%)$. These were followed by planning for discharge $(95 / 314,30.3 \%)$, continuity of patient care $(84 / 314,26.8 \%)$, and discharge education for patients and families (72/314, 22.9\%). The least common themes were medication reconciliation (24/314, 7.6\%), autonomy $(20 / 314,6.4 \%)$, and discharge education for providers $(17 / 314,5.4 \%)$. Discharge themes are summarized in Additional File 5.

\section{Facilitators and barriers to discharge}

Some elements of a successful transition in care were identified as being both a facilitator and a barrier. For example, patient demographic and clinical characteristics could be a facilitator due to an absence of co-morbidities $(49 / 314,15.6 \%)$, but also a barrier such as increased severity of illness and therefore, decreased likelihood of a "successful" ICU discharge (89/314, 28.3\%; e.g., as measured by Acute Physiology and Chronic Health Evaluation II (APACHE II) scores). For healthcare providers, common facilitators for a successful ICU discharge were provider-provider communication (77/314, 24.5\%; e.g., sufficient communication between ICU healthcare providers and those on the receiving ward), and critical care transition programs $(55 / 314,17.5 \%$; e.g., use of a nurse liaison or transition team that works with providers and patients for a smooth transition experience). Common barriers were provider workload (i.e., overburdened; $21 / 314,6.7 \%$ ) and a lack of provider-provider communication $(20 / 314,6.4 \%)$. Organizational facilitators included tools to facilitate discharge (50/314, 15.9\%; e.g., 
Table 3 Distribution of articles according to phase of care during discharge from ICU and quality of care frameworks

\begin{tabular}{|c|c|c|c|c|c|}
\hline Characteristic, n(\%) & All studies $(n=314)$ & Adult $(n=162)$ & Pediatric $(n=34)$ & Neonatal $(n=97)$ & $\begin{array}{l}\text { Not } \\
\text { reported } \\
(n=31)\end{array}$ \\
\hline \multicolumn{6}{|l|}{ Phase of care } \\
\hline Execution of discharge & $185(58.9)$ & $95(58.6)$ & $25(73.5)$ & $50(51.5)$ & $24(77.4)$ \\
\hline Post-discharge follow-up & $159(50.6)$ & 95 (58.6) & $13(38.2)$ & $45(46.4)$ & $11(35.5)$ \\
\hline Planning for discharge & $93(29.6)$ & $28(17.3)$ & $14(41.2)$ & $50(51.5)$ & $7(22.6)$ \\
\hline Evaluation for discharge & $42(13.4)$ & $17(10.5)$ & $5(14.7)$ & $17(17.5)$ & $3(9.7)$ \\
\hline \multicolumn{6}{|l|}{ Donabedian Framework } \\
\hline Process & $199(63.4)$ & $86(53.1)$ & $21(61.8)$ & $77(79.4)$ & $24(77.4)$ \\
\hline Outcome & $159(50.6)$ & $105(64.8)$ & $11(32.4)$ & $36(37.1)$ & $10(32.3)$ \\
\hline Structure & $94(29.9)$ & $44(27.2)$ & $18(52.9)$ & $25(25.8)$ & $14(45.2)$ \\
\hline \multicolumn{6}{|c|}{ Institute of medicine framework } \\
\hline Safe & $161(51.3)$ & $93(57.4)$ & $16(47.1)$ & $40(41.2)$ & $16(51.6)$ \\
\hline Patient-centered & $153(48.7)$ & $56(34.6)$ & $18(52.9)$ & $71(73.2)$ & $13(41.9)$ \\
\hline Effective & $112(35.7)$ & $54(33.3)$ & $16(47.1)$ & $36(37.1)$ & $13(41.9)$ \\
\hline Efficient & $85(27.1)$ & $48(29.6)$ & $13(38.2)$ & $18(18.6)$ & 13 (41.9) \\
\hline Timely & $54(17.2)$ & 37 (22.8) & $7(20.6)$ & $6(6.2)$ & $9(29.0)$ \\
\hline Equitable & $5(1.6)$ & $1(0.6)$ & $0(0.0)$ & $3(3.1)$ & $1(3.2)$ \\
\hline
\end{tabular}

Responses are not mutually exclusive across and within categories and add up to more than $100 \%$

guidelines) and the impact of current discharge practices on flow and performance $(36 / 314,11.5 \%$; e.g., a standardized workflow in place when handing a patient over from ICU to ward). Conversely, the impact of current discharge practices was also commonly identified as a barrier at the organizational level (49/314, 15.6\%; e.g., lack of standardized processes to facilitate discharge), and delays in discharge (32/314, 10.2\%; e.g., when a patient is ready to leave the ICU, but the discharge is delayed). All facilitators and barriers are summarized in Table 4, and the facilitators and barriers for each study are reported in Additional File 4.

\section{Tools to facilitate ICU discharge}

Forty-seven studies included tools to facilitate a successful ICU discharge (15.0\%). Of discharge tools described, most were guidelines or checklists (21/47, 44.7\%; procedures to standardize discharge planning and ensuring all steps are completed). Other tools identified include transfer tools $(7 / 47,14.9 \%$; procedures to facilitate an effective ICU to ward transfer), educational tools (4/7, $8.5 \%$; for patients and/ or family prior to discharge to prepare them), discharge assessments $(4 / 47,8.5 \%$; evaluating readiness for discharge and may include calculating risk for adverse events), discharge letters (3/47, 6.4\%; summarized information about the patient's ICU stay), transfer brochures $(2 / 47,4.3 \%$; information for patients and families about the transfer process), prediction tools $(2 / 47,4.3 \%$; to identify patients who may have adverse outcomes after discharge), triage models $(1 / 47,2.1 \%$; to identify patients with the greatest need of continued ICU care), and peer support programs (1/47, 2.1\%; facilitating space for family members and patients to connect about a shared experience). Of these 47 tools, 18 (38.3\%) were in adult populations, $16(34.0 \%)$ in neonatal populations, and six $(12.7 \%)$ in pediatric populations. A complete breakdown of available tools and study populations is available in Additional File 3.

\section{Discussion}

In this scoping review, we evaluated 314 articles that described a successful discharge from the ICU according to the phase of care examined, and the relevant Donabedian [34, 35] and IoM[38] framework elements. We identified facilitators and barriers to a successful ICU discharge at the patient and family, healthcare provider, and organizational levels. These include discharge education for patients and family members, communication between patients and healthcare providers and between healthcare providers themselves, and the use of tools to facilitate a successful discharge. Forty-seven articles described a discharge tool, where the majority of tools were guidelines or checklists, which institutions could adapt according to their institutional practices and unique patient populations.

Communication between patients and providers was an important facilitator for a successful ICU discharge as indicated by approximately one-quarter of included 
Table 4 Facilitators and barriers to care during discharge from the ICU

Factor

Facilitator/ Barrier

All studies

$\mathrm{n}(\%)$

$(\mathrm{N}=314)$

Patient/family

Facilitators

Discharge education for patients and families

$\begin{array}{lc}\text { Facilitator } & 82(26.1) \\ \text { Facilitator } & 80(25.5) \\ \text { Facilitator } & 77(24.5) \\ \text { Facilitator } & 49(15.6) \\ \text { Facilitator } & 26(8.3) \\ \text { Facilitator } & 25(8.0) \\ \text { Facilitator } & 4(1.3) \\ \text { Facilitator } & 4(1.3) \\ \text { Facilitator } & 3(1.0) \\ \text { Facilitator } & 3(1.0)\end{array}$

Family engagement/support system

$0(25.5)$

Provider-patient communication

Patient demographic and clinical characteristics

$26(8.3)$

Written communication for patients and families

$5(8.0)$

Patient/family are treated as members of the healthcare team

$4(1.3)$

Patient/family feelings of self-efficacy

Use of coping mechanisms

Excited, joyous to be leaving the ICU

Barriers

Patient demographic and clinical characteristics

Barrier

89 (28.3)

Feelings of patient and family anxiety, embarrassment

Barrier

$70(22.3)$

Expectations of patients/family

Barrier

$25(8.0)$

Physical and psychological effects of illness (e.g., pain, nightmares)

Barrier

$23(7.3)$

Lack of provider-patient communication

Barrier

$11(3.5)$

ICU and hospital length of stay

Barrier

$9(2.9)$

Financial obstacles (e.g., lack of insurance, cost of care)

Barrier

5 (1.6)

Socioeconomic factors of patient/family

Barrier

5 (1.6)

Logistical barriers to providing support (e.g., family lives far from hospital)

Barrier

Lack of familial support

Barrier

Feelings of lack of control

Barrier

Provider

Facilitators

Provider-provider communication

Facilitator

77 (24.5)

Critical care transition programs (e.g., outreach, liaison nurse)

Facilitator

55 (17.5)

Collaboration between ICU and ward

Facilitator

44 (14.0)

Written documentation for providers

Facilitator

42 (13.4)

Knowledge/experience of provider

Facilitator

$31(9.9)$

Clinical judgment or decision-making

Facilitator

$30(9.6)$

Clear roles/responsibility for providers

Facilitator

$17(5.4)$

Multidisciplinary team

Facilitator

8 (2.6)

Provider leadership

Facilitator

$1(0.3)$

Provider empathy to patient and family

Facilitator

$1(0.3)$

Barriers

Provider workload

Barrier

$21(6.7)$

Lack of provider-provider communication

Barrier

$20(6.4)$

Lack of knowledge/experience of provider

Barrier

$11(3.5)$

Provider anxiety

Barrier

Organizational

Facilitators

Tools to facilitate discharge

Facilitator

50 (15.9)

Impact of current discharge practices on flow and performance

Facilitator

36 (11.5)

Guidelines or policies

Facilitator

$31(9.9)$

Use of best practices

Facilitator

$30(9.6)$

Discharge location from ICU

Facilitator 
Table 4 (continued)

\begin{tabular}{|c|c|c|}
\hline Factor & Facilitator/ Barrier & $\begin{array}{l}\text { All studies, } \\
\mathrm{n}(\%) \\
(\mathrm{N}=314)\end{array}$ \\
\hline Education/training of providers & Facilitator & $29(9.2)$ \\
\hline Time of discharge (day of week or time of day) & Facilitator & $15(4.8)$ \\
\hline Availability of follow-up clinics or home support programs & Facilitator & $15(4.8)$ \\
\hline Admission location before ICU & Facilitator & $7(2.2)$ \\
\hline Hospital characteristics (e.g., trauma level) & Facilitator & $5(1.6)$ \\
\hline \multicolumn{3}{|l|}{ Barriers } \\
\hline Impact of current discharge practices on flow and performance & Barrier & $49(15.6)$ \\
\hline Delay in discharge & Barrier & $32(10.2)$ \\
\hline Time of discharge (day of week or time of day) & Barrier & $27(8.6)$ \\
\hline Discharge location from ICU & Barrier & $25(8.0)$ \\
\hline Limited ICU and ward resources & Barrier & $24(7.6)$ \\
\hline Costs of healthcare provided & Barrier & $20(6.4)$ \\
\hline Hospital characteristics (e.g., trauma level) & Barrier & $13(4.1)$ \\
\hline Hospital or ICU capacity & Barrier & $10(3.2)$ \\
\hline Admission location before ICU & Barrier & $5(1.6)$ \\
\hline Physical and technological infrastructure (e.g., small patient rooms, no electronic health records) & Barrier & $5(1.6)$ \\
\hline Lack of education/training of providers & Barrier & $4(1.3)$ \\
\hline Staffing (e.g., change in nurse-to-patient ratios, not enough staff) & Barrier & $4(1.3)$ \\
\hline Reduction in the levels of technology and monitoring when transition from ICU to ward & Barrier & $2(0.6)$ \\
\hline Restricted visitation policies & Barrier & $1(0.3)$ \\
\hline
\end{tabular}

Responses are not mutually exclusive within or across categories and add up to more than $100 \%$

studies. Some studies had similar findings about provider-patient communication, where patients and families valued summaries about the patient's stay in the ICU [40] and information about next steps [25, 41]. Patients and families also appreciated being an active member of the healthcare team when deciding if the patient was ready to transfer out of the ICU $[25,40]$. Communication between healthcare providers was also a facilitator to a successful ICU discharge; this included communication between the ICU care team and the hospital ward team, or the ICU care team and a patient's primary care provider. Communication between members of the healthcare team could be verbal (e.g., face-to-face, telephone) $[42,43]$, or written (e.g., a summary of the patients ICU stay in the medical chart) [42-44]. One study described the experience of nursing staff on a hospital ward, and how these nurses desired complete and coordinated information about an ICU patient [42]. The nurses on the ward described the benefits of having pre-planned transfers and open lines of communication so they could ask relevant follow-up questions to best care for the patient [42]. Other articles described the challenges that patients and primary care providers may encounter when a patient is discharged into the community [44, 45]. Primary care providers expressed interest in being provided information about the patient's ICU stay, and acknowledged that they do not have the same level of knowledge about the associated conditions that an intensivist would have $[44,45]$. Former patients echoed that it would be beneficial for both them and their primary care providers to have the information so they could address next steps for care together [44].

Approximately one-third of articles studied patient and family needs and experiences during the ICU discharge process, including their desire for consistent communication from the healthcare team, the experience of transitioning to a hospital ward with different staffing ratios, and the most common facilitator for a successful ICU discharge being education for patients and families. Ingram et al. [46] found that education about the discharge process reduced post-discharge emergency room visits and overall costs associated with care. Others have found that addressing the needs of patients, based in Maslow's hierarchy of needs framework (e.g., physical, emotional) [47] can influence a successful ICU discharge process [48]. By anticipating a patient's concerns and involving their family in support and care for the patient, ICUs can promote a patient- and family- centered approach [49]. Burns and colleagues provided suggestions to incorporate successful patient- and family- centered care and improve engagement in the ICU; these included offering opportunities for patients and families to provide feedback (ranging 
from short, anonymous surveys to being members of a committee) and encouraging flexibility from care providers and researchers when responding to patients and families in these settings [50]. These reviews and our data demonstrate that patient and family needs should be considered when designing effective discharge criteria and guidelines.

\section{Strengths and limitations}

Our scoping review has several strengths. Our search strategy was developed with an academic librarian who has experience in systematic and scoping reviews and included multiple databases. We used established review methodology where appropriate, and our search was not restricted by language. By translating articles, we were able to capture more tools and discussions about the discharge process from several global areas, versus Englishspeaking countries alone. Another strength of our study is the inclusion of secondary research, including reviews and editorials. We screened conference proceedings to identify additional relevant full-text articles that may not have been indexed to appear in the database search. Despite our comprehensive search strategy there is still the chance that we missed articles. There were cases where full-text articles were unavailable, and the translation of some non-English articles may have left out pertinent information. We did not directly email authors of articles where we were unable to retrieve a full-text copy of a publication, whether this was a conference abstract or a publication in a non-English language journal. We reached out to some authors via ResearchGate, and utilized two institutional access databases and inter-facility loans to retrieve as many articles as possible without purchasing additional accesses. The categorization of the articles while conducting the review is subjective; not all studies clearly define which framework (phases of care, Donabedian, and IoM) elements were the focus of their study. Despite team members' training and review of these frameworks prior to data abstraction, and verification by a second reviewer, it is possible articles may have been misclassified. Finally, as this is a scoping review, the results reported are high-level information about a successful ICU discharge and may benefit from a systematic review to further describe the impacts of certain practices on ICU discharges.

\section{Conclusions}

Using IoM [38] and Donabedian [34, 35] frameworks for high-quality care, we identified several themes, facilitators, and barriers to successful ICU discharges across adult, pediatric, and neonatal populations. Commonly reported facilitators to a successful ICU discharge included the education and engagement of patients and family members in the process, and communication between healthcare providers. Future reviews could provide more insight on the impacts of patient and family needs and experiences. Tools to facilitate discharge could utilize elements from these tools and adapt them to their own circumstances to provide discharge tools that facilitate successful transitions in care from the ICU to the hospital ward or home.

\begin{abstract}
Abbreviations
APACHE-II: Acute Physiology and Chronic Health Evaluation II; loM: Institute of medicine; ICU: Intensive care unit; JCI: Joint Commission International; NICU: Neonatal Intensive care unit; PICU: Pediatric intensive care unit; PRISMA-SCR: Preferred reporting items for systematic reviews and meta-analyses: scoping review; RCT: Randomized control trial; WHO: World Health Organization.
\end{abstract}

\section{Supplementary Information}

The online version contains supplementary material available at https://doi. org/10.1186/s13054-021-03857-2.

Additional file 1. Preferred Reporting Items for Systematic reviews and Meta-Analyses extension for Scoping Reviews (PRISMA-SCR) Checklist

Additional file 2. MEDLINE Search Strategy

Additional file 3. Tools to facilitate a successful ICU discharge

Additional file 4. Article classification according to study population, describing framework elements, themes, and facilitators and barriers

Additional file 5. Discharge themes of articles included in the review

\section{Acknowledgements}

The authors would like to thank Carmen Hiploylee with their help in running the search strategy, title and abstract screening, full-text screening, and data abstraction. They would also like to thank Ashton Dougan for their help with title and abstract screening, full-text screening, and data abstraction, Kira Makuk for assistance in data verification and table preparation, and Olesya Dmitrieva, Janet Wong, Regan King, and Melanie Anglin for their assistance in data abstraction and verification.

\section{Authors' contributions}

KMF \& HTS, conception and guarantors. KP, running search and database management. KP, KS, NF, SL, KK, title and abstract screening. KP, KS, KK, full-text screening. KP, KS, KK, data abstraction. KP, KS, KK, data verification. KK \& KP, statistical analyses. KP, drafting manuscript. All authors provided critical reviews to the manuscript. All authors read and approved the final manuscript.

\section{Funding}

This work is funded by the Canadian Institutes of Health Research Transitions in Care Team Grant (Grant No. 423947). The funder of the study had no role in study design, data collection, data analysis, data interpretation, or writing of the manuscript.

Availability of data and materials

Data sharing is not applicable to this article as no datasets were generated or analysed during the current study.

\section{Declarations}

Ethics approval and consent to participate Not applicable. 


\section{Consent for publication \\ Not applicable.}

\section{Competing interests}

The authors declare that they have no competing interests.

\section{Author details}

'Department of Critical Care Medicine, Cumming School of Medicine, University of Calgary and Alberta Health Services, 3134 Hospital Drive NW, Calgary, AB T2N 4Z6, Canada. ${ }^{2}$ Knowledge Translation Program, Li Ka Shing Knowledge Institute, St. Michael's Hospital, 209 Victoria Street, East Building, Toronto, ON M5B 1W8, Canada. ${ }^{3}$ Department of Geriatric Medicine, Faculty of Medicine, University of Toronto, 6 Queen's Park Crescent West, Third Floor, Toronto, ON M5S 3H2, Canada. ${ }^{4}$ Department of Community Health Sciences and O'Brien Institute for Public Health, Cumming School of Medicine, University of Calgary, 3134 Hospital Drive NW, Calgary, AB T2N 4Z6, Canada. ${ }^{5}$ Faculty of Health, School of Health Administration, Dalhousie University, Sir Charles Tupper Medical Building, 2nd Floor, 5850 College Street, Halifax, NS B3H 4R2, Canada. ${ }^{6}$ Hotchkiss Brain Institute, Cumming School of Medicine, University of Calgary, 3134 Hospital Drive NW, Calgary, AB T2N 4Z6, Canada. ${ }^{7}$ Department of Psychiatry, Cumming School of Medicine, University of Calgary and Alberta Health Services, 3134 Hospital Drive NW, Calgary, AB T2N 4Z6, Canada.

\section{Received: 8 September 2021 Accepted: 4 December 2021}

\section{Published online: 17 December 2021}

\section{References}

1. Naylor M, Keating SA. Transitional care: moving patients from one care setting to another. Am J Nurs. 2008;108(9 Suppl):58-63.

2. Bell CM, Brener SS, Gunraj N, Huo C, Bierman AS, Scales DC, Bajcar J, Zwarenstein M, Urbach DR. Association of ICU or hospital admission with unintentional discontinuation of medications for chronic diseases. JAMA. 2011:306(8):840-7.

3. Stelfox HT, Bourgault AM, Niven DJ. De-implementing low value care in critically ill patients: a call for action-less is more. Intensive Care Med. 2019:45:1443-6.

4. Garrouste-Orgeas M, Timsit JF, Vesin A, Schwebel C, Arnodo P, Lefrant JY, Souweine B, Tabah A, Charpentier J, Gontier O, et al. Selected medical errors in the intensive care unit: results of the IATROREF study: parts I and II. Am J Respir Crit Care Med. 2010;181(2):134-42.

5. Camiré E, Moyen E, Stelfox HT. Medication errors in critical care: risk factors, prevention and disclosure. CMAJ. 2009;180(9):936-43.

6. Chaboyer W, Kendall E, Kendall M, Foster M. Transfer out of intensive care: a qualitative exploration of patient and family perceptions. Aust Crit Care. 2005;18(4):138-45.

7. Li P, Stelfox HT, Ghali WA. A prospective observational study of physician handoff for intensive-care-unit-to-ward patient transfers. Am J Med. 2011:124(9):860-7.

8. Leith BA. Transfer stress and medical intensive care patients and family members. Dynamics. 2001;12(3):22-7.

9. Stelfox HT, Niven DJ, Clement FM, Bagshaw SM, Cook DJ, McKenzie E, Potestio ML, Doig CJ, O’Neill B, Zygun D. Stakeholder engagement to identify priorities for improving the quality and value of critical care. PLoS ONE. 2015;10(10):e0140141.

10. Potestio ML, Boyd JM, Bagshaw SM, Heyland D, Oxland P, Doig CJ, Zygun $D$, Stelfox HT. Engaging the public to identify opportunities to improve critical care: a qualitative analysis of an open community forum. PLoS ONE. 2015;10(11):e0143088.

11. Finfer S. Critical care —an all-encompassing specialty. N Engl J Med. 2013;369(7):669-70.

12. Desai SV, Law TJ, Needham DM. Long-term complications of critical care. Crit Care Med. 2011;39(2):371-9.

13. Warwick M, Fernando SM, Aaron SD, Rochwerg B, Tran A, Thavorn K, Mulpuru S, Mclsaac DI, Thompson LH, Tanuseputro P et al. Outcomes and resource utilization among patients admitted to the intensive care unit following acute exacerbation of chronic obstructive pulmonary disease. J Intensive Care Med 2020:1-7.

14. Nates JL, Nunnally M, Kleinpell R, Blosser S, Goldner J, Birriel B, Fowler CS, Byrum D, Miles WS, Bailey H, et al. ICU admission, discharge, and triage guidelines: a framework to enhance clinical operations, development of institutional policies, and further research. Crit Care Med. 2016:44(8):1553-602

15. de la Oliva P, Cambra-Lasaosa FJ, Quintana-Diaz M, Rey-Galan C, Sanchez-Diaz Jl, Martin-Delgado MC, de Carlos-Vicente JC, HernandezRastrollo R, Holanda-Pena MS, Pilar-Orive FJ, et al. Admission, discharge and triage guidelines for paediatric intensive care units in Spain. Med Intensiva. 2018;42(4):235-46.

16. Nates JL, Nunnally M, Kleinpell R, Blosser S, Goldner J, Birriel B, Fowler CS, Byrum D, Miles WS, Bailey H, et al. ICU admission, discharge, and triage guidelines: A framework to enhance clinical operations, development of institutional oolicies, and further research. Crit Care Med. 2016:44(8):1553-602.

17. Giudici L, Rodriguez D, Alonso MM, Bertani G, Cattaino A, Fernandez P, Aguilera NM, Muniagurria G, Marzan G, Pose G. Guidelines for discharge planning of the high risk newborn. Arch Argent Pediatr. 2018;116(4):S77-81.

18. Hervé MEW, Zucatti PB, Lima MADS. Transition of care at discharge from the intensive care unit: a scoping review. Rev Latino-Am Enfermagem. 2020:28:e3325

19. Häggström M, Asplund K, Kristiansen L. To reduce technology prior discharge from intensive care-Important but difficult? Scand J Caring Sci. 2013;27(3):506-15.

20. Elliott M, Worrall-Carter $L$, Page K. Factors contributing to adverse events after ICU discharge: a survey of liasion nurses. Aust Crit Care 2013;26(2):76-80.

21. Leeb K, Jokovic A, Sandhu M, Zinck G. Intensive care in Canada. Healthc Q. 2006;9(1):32-3.

22. Hosein FS, Bobrovitz N, Berthelot S, Zygun D, Ghali WA, Stelfox HT. A systematic review of tools for predicting severe adverse events following patient discharge from intensive care units. Crit Care. 2013;17(3):R102.

23. Angus DC, Barnato AE, Linde-Zwirble WT, Weissfeld LA, Watson RS, Rickert T. Rubenfeld GDobotRWJFIE-o-LPG: use of intensive care at the end of life in the United States: an epidemiologic study. Crit Care Med. 2004;32(3):638-43.

24. Adhikari NKJ, Fowler RA, Bhagwanjee S, Rubenfeld GD. Critical care and the global burden of critical illness in adults. Lancet. 2010;376(9749):1339-46.

25. de Grood C, Parsons Leigh J, Bagshaw S, Dodek PM, Fowler RA, Forster AJ, Boyd JM, Stelfox HT. Patient, family and provider experiences with transfers from intensive care unit to hospital ward: a multicentre qualitative study. CMAJ. 2018;190:E669-76.

26. World Health Organization: Transitions of care: Technical series on safer primary care. In: Geneva, Switzerland; 2016.

27. Stelfox HT, Lane D, Boyd JM, Taylor S, Perrier L, Straus S, Zygun D, Zuege DJ. A scoping review of patient discharge from intensive care: opportunities and tools to improve care. Chest. 2015;147(2):317-27.

28. Stelfox HT, Soo A, Niven DJ, Fiest KM, Wunsch H, Rowan KM, Bagshaw SM. Assessment of the safety of discharging select patients directly home from the intensive care unit: a multicenter population-based cohort study. JAMA Intern Med. 2018;178(10):1390-9.

29. Basmaji J, Lau V, Lam J, Priestap F, Ball IM. Lessons learned and new directions regarding discharge direct from adult intensive care units sent home (DISH): a narrative review. J Intensive Care Soc. 2019;20(2):165-70

30. Lau VI, Priestap FA, Lam JNH, Ball IM. Factors associated with the increasing rates of discharges directly home from intensive care units: a direct from ICU Sent Home Study. J Intensive Care Med. 2018;33(2):121-7.

31. Arksey H, O'Malley L. Scoping studies: Towards a methodolgical framework. Int J of Soc Res Methodol. 2005;8(1):19-32.

32. Levac D, Colquhoun $\mathrm{H}, \mathrm{O}$ 'Brien KK. Scoping studies: advancing the methodology. Implement Sci 2010;5(69):1-9.

33. Tricco AC, Lillie E, Zarin W, O'Brien KK, Colquhoun H, Levac D, Moher D, Peters MD, Horsley T, Weeks L, et al. PRISMA extension for scoping reviews (PRISMA-SCR): checklist and explanation. Ann Intern Med. 2018;169(7):467-73

34. Donabedian A. The definition of quality and approaches to its assessment, vol. 1. Ann Arbor, Ml: Health Administration Press; 1980.

35. Donabedian A. Evaluating the quality of medical care, 1966. Milbank Q. 2005:83(4):691-729. 
36. Google Translate [https://translate.google.com/]

37. Jackson JL, Kuriyama A, Anton A, Choi A, Fournier J-P, Geier A-K, Jacquerioz F, Kogan D, Sun R. The accuracy of Google Translate for abstracting data from non-english-language trials for systematic reviews. Ann Intern Med. 2019;171(9):677-9.

38. Institute of Medicine Committee on the Quality of Health Care in America: Crossing the quality chasm: a new health system for the 21 st century. Washington, DC: National Academy Press; 2001.

39. Ebrahimian A, Fakhr-Movahedi A, Ghorbani R, Ghasemian-Nik H. Development inverse triage system in intensive care units using APACHE ॥ scoring system for emergency situation: Brief report. Tehran Univ Med J. 2018;76(7):492-7.

40. Agard AS, Hofhuis JGM, Koopmans M, Gerritsen RT, Spronk PE, Engelberg RA, Randall Curtis J, Zijlstra JG, Jensen HI. Identifying improvement opportunities for patient- and family-centered care in the ICU: Using qualitative methods to understand family perspectives. J Crit Care. 2019:49:33-7.

41. Burnham N, Feeley N, Sherrard K. Parents' perceptions regarding readiness for their infant's discharge from the NICU. Neonatal Netw. 2013;32(5):324-34.

42. Enger R, Andershed B. Nurses' experience of the transfer of ICU patients to general wards: A great responsibility and a huge challenge. J Clin Nurs. 2018;27(1-2):e186-94.

43. James S, Quirke S, McBride-Henry K. Staff perception of patient discharge from ICU to ward-based care. Nurs Crit Care. 2013;18(6):297-306.

44. Bench S, Cornish J, Xyrichis A. Intensive care discharge summaries for general practice staff: a focus group study. $\mathrm{Br} J \mathrm{Gen}$ Pract. 2016;66(653):e904-12.

45. Zilahi G, O'Connor E. Information sharing between intensive care and primary care after an episode of critical illness. A mixed methods analysis. PLoS ONE. 2019;14(2):e0212438.

46. Ingram JC, Powell JE, Blair PS, Pontin D, Redshaw M, Manns S, Beasant L, Burden H, Johnson D, Rose C, et al. Does family-centred neonatal discharge planning reduce healthcare usage? A before and after study in South West England. BMJ Open. 2016;6(3):e010752.

47. Maslow AH. A theory of human motivation. Psychol Rev. 1943;50:370-96.

48. King J, O'Neill B, Ramsay P, Linden MA, Darweish Medniuk A, Outtrim J, Blackwood B. Identifying patients'support needs following critical illness: a scoping review of the qualitative literature. Crit Care. 2019;23(1):187.

49. Davidson JE, Aslakson RA, Long AC, Puntillo KA, Kross EK, Hart J, Cox CE, Wunsch H, Wickline MA, Nunnally ME, et al. Guidelines for familycentered care in the neonatal, pediatric, and adult ICU. Crit Care Med. 2017;45(1):103-28.

50. Burns KEA, Misak C, Herridge M, for the Patient and Family Partnership Committee of the Canadian Critical Care Trials Group, et al. Patient and family engagement in the ICU: untapped opportunities and underrecognized challenges. Am J Respir Crit Care Med. 2018;198(3):310-9.

\section{Publisher's Note}

Springer Nature remains neutral with regard to jurisdictional claims in published maps and institutional affiliations.

Ready to submit your research? Choose BMC and benefit from:

- fast, convenient online submission

- thorough peer review by experienced researchers in your field

- rapid publication on acceptance

- support for research data, including large and complex data types

- gold Open Access which fosters wider collaboration and increased citations

- maximum visibility for your research: over $100 \mathrm{M}$ website views per year

At BMC, research is always in progress.

Learn more biomedcentral.com/submissions 